\title{
RPR revisited (2): Long-term farmer experience helps define the role of RPR in grazed pastures
}

\author{
M. ZAMAN ${ }^{1}$ and B. F. QUIN ${ }^{2}$ \\ ${ }^{1}$ Ballance Agri-Nutrients Ltd, Private Bag 12503, Tauranga 3143, New Zealand \\ ${ }^{2}$ Quin Environmentals (NZ) Ltd, PO Box 125122, St Heliers, Auckland 1740, NewZealand \\ quinfert@xtra.co.nz
}

\begin{abstract}
The commercial introduction of reactive phosphate rock (RPR) to the New Zealand market in 1987 was the subject of much dispute regarding its efficacy, and the differing interpretations of field trial results. Twenty-five years on, it was considered time to seek the views of farmers who are long-term users of RPR, across a wide range of geographic, soil type, fertility, climate and farming operations. The fact that the farmers interviewed have all been farming successfully with RPR for many years enables conditions suitable for RPR use to be identified more clearly compared to earlier advice. This progress is discussed in the context of utilising the proven reduced phosphorus $(\mathrm{P})$ run-off with RPR to reduce $\mathrm{P}$ eutrophication in $\mathrm{P}$-sensitive catchments.
\end{abstract}

Key words: Reactive phosphate rock, RPR, superphosphate, SSP, long-term use, phosphorus runoff, eutrophication, water quality, recommendations

\section{Introduction}

Reactive phosphate rock (RPR) has been commercially available as a sustained-release phosphorus $(\mathrm{P})$ fertiliser for pasture from a variety of suppliers in New Zealand for 25 years. In the early years of its promotion and use, its efficacy was the subject of controversy (Quin $\&$ Zaman 2012). It has been used as the sole source of $\mathrm{P}$ by some farmers and in combination with soluble $\mathrm{P}$ sources by others. In most locations in New Zealand, it needs to be blended with elemental sulphur (S) to prevent $\mathrm{S}$ deficiency in pasture.

Quin \& Zaman (2012) re-evaluated data from the 19-site "National Series" of RPR vs soluble P mown plot trials. Over the period of these trials (3-6 years, depending on the site), pasture production with RPR equalled that with soluble $\mathrm{P}$ from the third year of use. Research with partially phosphoric-acidulated RPRs (PAPRs) has demonstrated that these equal the performance of fully-soluble $\mathrm{P}$ from the first year of use (Mackay \& Wewala 1990; Rajan \& Marwaha 1993). Products made by incorporating RPR into SSP were not as effective (Ledgard et al. 1992). For cost and variability control reasons, the great majority of field trial comparisons of RPR with soluble P fertilisers have been conducted under mowing and partial clippings return (Quin \& Zaman 2012). There is some evidence from the small number of trials conducted under grazing that RPR performs better in some real-life grazing conditions (Mackay 1990; McBride 1992; Thomson \& Roberts 1995).

\section{Details of RPR-user survey}

Given the length of time RPR has been commercially available in New Zealand, and the increasing attention being drawn to the proven lower $\mathrm{P}$ run-off losses associated with RPR, it was decided to interview a number of farmers who have continued to use RPRbased fertiliser as their predominant $(>75 \%$ on a $\mathrm{P}$ basis) $\mathrm{P}$ input long-term. Ballance Agri-Nutrients Ltd kindly provided client lists, who were telephoneinterviewed by Ballance field staff. In the North Island, the minimum time RPR had been used by farmers for inclusion in the survey was able to be set at 10 years. The more recent history of RPR in the South Island, and the fact that RPR was more commonly used blended with sufficient diammonium phosphate (DAP) or triple superphosphate (TSP) to provide $30-50 \%$ of the total $\mathrm{P}$, meant a 7 -year minimum was set to get wider representation in the survey.

Farmers were asked to verify the type of farm, and provide the annual rainfall and their history of RPR use. In answer to an informal Question 1 (not reported here), most could recall the brand-name of the product they originally used (Clover King being by far the most common), but did not know the actual source of the RPR they were currently being supplied with. However all expressed satisfaction with the RPRs they had used, and relied on their supplier to provide an acceptable product. Soil fertility data was checked against the farmers' records. Averages and deviations by region are given in Table 1 . A series of six set formal questions was then asked of each farmer (Tables 2-7). The logic behind each question will be given in the relevant section. The questions were not asked in a "multi-choice" format. Rather, the farmers' answers to these questions were written down in full, and then categorised (Tables 2-7) to save space. The full answers have been kept on file, and are available to research institutions on request to the senior author. 
Table 1. Average soil properties of different regions where the survey was conducted.

\begin{tabular}{lcccccccc}
\hline Region & Farm \# & Rainfall $(\mathrm{mm})$ & $\begin{array}{c}\text { Use of } \\
\text { RPR } \\
(\mathrm{yrs})\end{array}$ & $\begin{array}{c}\text { P application } \\
\text { rate }(\mathrm{kg} \mathrm{P} / \\
\text { ha/yr) }\end{array}$ & $\begin{array}{c}\text { P retention } \\
(\%)\end{array}$ & $\mathrm{pH}$ & $\begin{array}{c}\text { Olsen P } \\
(\mathrm{mg} / \mathrm{l})\end{array}$ & $\begin{array}{c}\text { Resin } \mathrm{P} \\
(\mathrm{mg} / \mathrm{kg})\end{array}$ \\
1 & $1-9$ & $1555 \pm 287$ & $19 \pm 5$ & $28 \pm 4$ & $32 \pm 13$ & $5.6 \pm 0.2$ & $24 \pm 8$ & $72 \pm 18$ \\
2 & $10-27$ & $1475 \pm 164$ & $13 \pm 2.9$ & $38 \pm 8$ & $76 \pm 13$ & $5.7 \pm 0.2$ & $38 \pm 17$ & $104 \pm 48$ \\
3 & $28-39$ & $1367 \pm 484$ & $15 \pm 4.6$ & $43 \pm 12$ & $80 \pm 6.2$ & $5.8 \pm 0.2$ & $45 \pm 8.2$ & $101 \pm 25$ \\
4 & $40-42$ & $1375 \pm 120$ & $20 \pm 1$ & $18 \pm 1$ & $62 \pm 12$ & $5.5 \pm 0.2$ & $22 \pm 5$ & $45 \pm 6$ \\
5 & $43-45$ & $1375 \pm 100$ & $18 \pm 1$ & $20 \pm 1$ & $72 \pm 18$ & $5.6 \pm 0.3$ & $24 \pm 8$ & $32 \pm 9$ \\
6 & $46-49$ & $925 \pm 80$ & $10 \pm 7$ & $28 \pm 12$ & $37 \pm 11$ & $5.9 \pm 0.3$ & $21 \pm 6$ & $52 \pm 15$ \\
7 & $50-52$ & $990 \pm 100$ & $10 \pm 2$ & $26 \pm 2$ & $33 \pm 6$ & $5.9 \pm 0.3$ & $18 \pm 3$ & $46 \pm 5$ \\
8 & $53-54$ & $4000 \pm 290$ & $6 \pm 0$ & $31 \pm 4$ & $32 \pm 4$ & $5.8 \pm 0.1$ & $22 \pm 4$ & $53 \pm 11$ \\
\hline
\end{tabular}

$1=$ Northland, 2= Waikato, 3= Taranaki, 4= Gisborne, 5 = Hawkes Bay, 6 = Canterbury,

$7=$ Lower South Island, $8=$ West Coast

Table 2. What made you to try RPR in the first place?

\begin{tabular}{|c|c|c|c|c|}
\hline \multirow[t]{2}{*}{ Farmer comments } & \multicolumn{3}{|c|}{ Percentage of } & \multirow[t]{2}{*}{ *Farm \# } \\
\hline & All Farms & Dairy & S\&B & \\
\hline Fertiliser rep recommended & 24 & 9 & 32 & $\begin{array}{l}2,9,10,11,26,28,31,32,34,37 \\
38,46,52\end{array}$ \\
\hline Followed what father did & 4 & 3 & 5 & 36,43 \\
\hline It was my idea; I wanted something new & 24 & 31 & 10 & $\begin{array}{l}1,8,18,24,29,30,33,39,47,50, \\
51,53,54\end{array}$ \\
\hline Cost advantage & 15 & 11 & 21 & $3,5,7,13,35,40,41,48$ \\
\hline Environmental benefits & 20 & 20 & 21 & $\begin{array}{l}4,12,15,16,17,21,25,27,44, \\
45,49\end{array}$ \\
\hline Specific concerns regarding SSP & 13 & 14 & 26 & $6,14,19,20,22,23,42$ \\
\hline
\end{tabular}

* Farm numbers in italics represent sheep and beef (S\&B) farms

Table 3. Did you notice any change in pasture production after changing to RPR?

\begin{tabular}{|c|c|c|c|c|}
\hline \multirow[t]{2}{*}{ Farmer comments } & \multicolumn{3}{|c|}{ Percentage of } & \multirow[t]{2}{*}{ *Farm \# } \\
\hline & All Farms & Dairy & S\&B & \\
\hline No change & 33 & 29 & 42 & $\begin{array}{l}1,3,4,5,8,26,28,30,33,36,42 \\
45,48,49,51,52,53,54\end{array}$ \\
\hline No real change/no change really & 24 & 29 & 16 & $\begin{array}{l}9,14,15,16,18,19,35,37,38,39 \\
40,43,44\end{array}$ \\
\hline Good from the start & 17 & 14 & 21 & $2,6,7,12,17,20,25,41,46$ \\
\hline Steady improvement right from the start & 13 & 11 & 16 & $11,21,22,23,24,27,50$ \\
\hline Slight decline then recovered & 13 & 20 & 0 & $10,13,29,31,32,34,47$ \\
\hline Permanent reduction & 0 & 0 & 0 & nil \\
\hline
\end{tabular}

${ }^{*}$ Farm numbers in italics represent sheep and beef (S\&B) farms

Table 4. Have you noticed any change in stock health after changing to RPR?

\begin{tabular}{lcccl}
\hline Farmer comments & \multicolumn{2}{c}{ Percentage of } & \multicolumn{2}{l}{ *Farm \# } \\
& All Farms & Dairy & S\&B & \\
\hline No change & 57 & 51 & 68 & $\begin{array}{l}1,2,3,4,5,7,8,9,12,13,24,25, \\
26,28,30,31,32,33,35,37,38, \\
\end{array}$ \\
Possible improvement & & & & $39,42,44,46,47,48,49,51,53,54$ \\
Was good before, now better & 13 & 14 & 10 & $11,19,20,21,36,40,45$ \\
Definitely yes - reasons given & 4 & 6 & 0 & 10,34 \\
& 26 & 23 & 32 & $\begin{array}{l}6,14,15,16,17,18,22,23,27,29, \\
\text { Worse/possibly worse }\end{array}$ \\
\hline
\end{tabular}

* Farm numbers in italics represent sheep and beef (S\&B) farms 
Table 5. Are you happy with the use of RPR, and do you intend to keep using it?

\begin{tabular}{|c|c|c|c|c|}
\hline \multirow[t]{2}{*}{ Farmer comments } & \multicolumn{3}{|c|}{ Percentage of } & \multirow[t]{2}{*}{ *Farm \# } \\
\hline & All Farms & Dairy & S\&B & \\
\hline Yes & 20 & 35 & 16 & $\begin{array}{l}4,8,12,13,14,26,28,30,33,45 \\
50\end{array}$ \\
\hline Yes with reasons & 68 & 66 & 74 & $\begin{array}{l}1,2,6,7,9,10,11,15,17,18,20, \\
21,22,23,24,25,27,29,32,34, \\
35,36,37,38,39,40,41,42,43, \\
44,46,47,48,49,51,52,54\end{array}$ \\
\hline Yes with price provision & 7 & 9 & 5 & $5,19,31,53$ \\
\hline Might use some soluble $P$ with it & 2 & 0 & 5 & 3 \\
\hline No - price is too high & 2 & 2 & 0 & 16 \\
\hline
\end{tabular}

${ }^{*}$ Farm numbers in italics represent sheep and beef (S\&B) farms

Table 6. Do you know any farmers who have stopped using RPR and why?

\begin{tabular}{|c|c|c|c|c|}
\hline \multirow[t]{2}{*}{ Farmer comments } & \multicolumn{3}{|c|}{ Percentage of } & \multirow[t]{2}{*}{ *Farm \# } \\
\hline & All Farms & Dairy & S\&B & \\
\hline No & 87 & 86 & 89 & $\begin{array}{l}1,2,3,4,5,6,7,8,10,11,12,14, \\
15,16,17,18,19,21,22,23,24, \\
25,26,27,28,29,31,32,33,34, \\
35,36,37,38,39,40,41,42,43, \\
45,46,47,48,49,51,52,54\end{array}$ \\
\hline $\begin{array}{l}\text { Yes - not enough growth soon enough/fertility } \\
\text { too low at start }\end{array}$ & 6 & 6 & 5 & $13,30,50$ \\
\hline $\begin{array}{l}\text { Yes - because of drought have stopped us- } \\
\text { ing fertiliser }\end{array}$ & 2 & 0 & 5 & 44 \\
\hline Yes - price or no local store & 6 & 9 & 0 & $9,20,53$ \\
\hline
\end{tabular}

${ }^{*}$ Farm numbers in italics represent sheep and beef (S\&B) farms

Table 7. What advice would you give to a farmer interested in switching to RPR?

\begin{tabular}{lllll}
\hline Farmer comments & $\begin{array}{l}\text { Percentage of } \\
\text { All Farms }\end{array}$ & Dairy & S\&B & *Farm \# \\
\hline Just give it time - it will get there & 20 & 26 & 10 & $\begin{array}{l}10,11,12,34,35,36,37,46,47, \\
\end{array}$ \\
It works for me - give it a go/go for it! & 61 & 57 & 63 & $\begin{array}{l}1,2,5,6,7,8,9,14,15,16,17, \\
18,19,20,21,22,23,24,26,27, \\
\end{array}$ \\
Have good soil fertility to start & & & & $29,31,40,41,42,43,44,45,49$, \\
Get good advice & 9 & & $50,51,52$, \\
Make sure is spread well & 6 & 11 & 5 & $4,13,25,33,39$, \\
No need for advice & 4 & 6 & 5 & $3,30,38$ \\
\hline
\end{tabular}

* Farm numbers in italics represent sheep and beef (S\&B) farms

All 54 farmers who were contacted (35 dairy, and 19 sheep and beef/dry stock) answered all the questions set. The farms are identified only by a number. The distribution of the farms is shown in Fig.1. Many, but not all, of the surveyed farmers were ex-clients of Summit-Quinphos (NZ) Ltd before its purchase by Ballance in 2007, and are now mainly supplied and advised by the Altum division of Ballance.

\section{Characteristics of surveyed farms}

The surveyed farms covered a typical range of soil types, rainfall, soil $\mathrm{P}$ fertility and $\mathrm{pH}$ (Table 1). A high proportion of the surveyed farmers were using the Resin P test found by Saggar et al. (1999), indicating farmer satisfaction with its ability to provide a reliable indication of the amount of RPR reserves in the soil, and its supply to plants. 


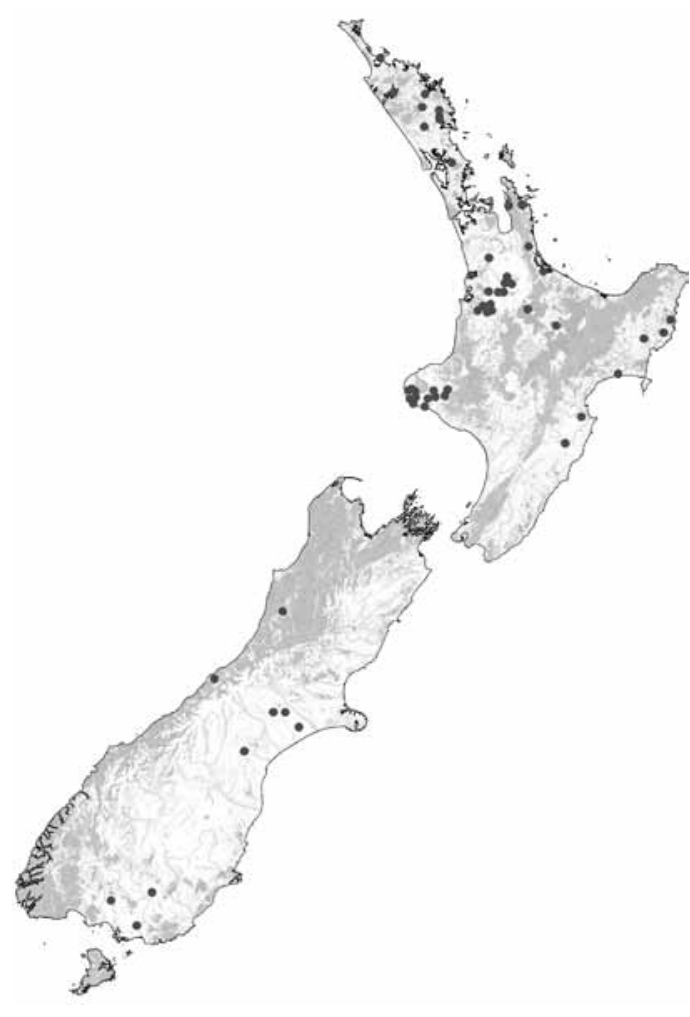

Figure 1. Distribution of surveyed farms.

As a spin-off from this survey, it was hoped to get a good comparison between soil $\mathrm{P}$ soil tests in the earlier and later years of using RPR. This proved to be more difficult than expected. The early soil testing traditionally covered a wide range of paddocks on the farm, in order to get a good understanding of soil fertility across the farm, and hence its suitability for RPR. Subsequently, those paddocks with lower fertility tended to be soil tested more frequently, as a check on short-term fertiliser requirements, and it was recommended that those with excessively high fertility levels had fertiliser application reduced or even withheld, until levels were in the optimum range. Both actions bring about a reduction in "average" soil tests over time. A comparison of earliest available, mid-years, and most recently available soil tests from farms where documented same paddock histories are available will be presented in a future paper. As a general observation however, the application rates being applied annually maintained both Olsen P and Resin P levels over time.

Not surprisingly, regions where the majority of the farms surveyed were dairy farms, and where ash soils predominated, had the highest soil P levels (Table 1), with averages of 38 and 45 Olsen $P$ in the Waikato and Taranaki respectively (probably slightly lower than typical for farms using soluble $\mathrm{P}$ in these areas), and
104 and 101 Resin P. The ratio of Resin P to Olsen P was generally similar to the $2.3-3.0$ ratio found by Saggar et al. (1999). However, farms with the lowest soil $\mathrm{pH}$ levels in this survey, viz those in Hawke's Bay (average soil $\mathrm{pH}$ 5.2), the Resin P to Olsen P ratio was only 1.3. This reflects the very high RPR dissolution rates in these conditions; in effect meaning that the behavior of RPR is more similar to soluble $\mathrm{P}$ than in other conditions.

The relatively high average soil $\mathrm{pH}$ in the Canterbury and Southland farms surveyed probably reflects the availability and low cost of lime in these areas. None of the farmers in these areas reported any lag-phase after switching to RPR (Table 3). This suggests that the true soil $\mathrm{pH}$ limit for RPR use is significantly higher than previously assumed, at least under higher rainfall or irrigation.

\section{Discussion on answers to individual formal questions Q.2 "What made you try RPR in the first place?"}

This question was posed to throw some light on what were the primary factors influencing a farmer to change the type of fertiliser being used. The answers to this question (Table 2) show a mix of farmer interests, willingness to try something new, concerns with costs and other aspects of their previous fertiliser, environmental awareness and concerns, relationships with company field staff and confidence in their recommendations, and trust in RPR suppliers.

\section{Q.3 "Did you notice any change in pasture production after changing to RPR?"}

This question was posed to compare the significance of the small but scientifically proven (at least in mown plot trials) lag-phase with farmer experience. Fully $74 \%$ of farmers answered "good from the start", "no change" or "not really any change" to this question (Table 3). Only $13 \%$ noted or implied a small decline initially. This was matched by a similar percentage who noted a steady improvement from the start (relative to previous type of fertiliser used, with no lag-phase), and noted benefits such as higher clover content in the sward, and "hanging on better in hard times". These answers could reflect in part the relatively low year-to-year responses to fertiliser $\mathrm{P}$ under maintenance $\mathrm{P}$ regimes. Dairy farmers are generally able to assess much smaller changes in production via milk production, but the percentage of dairy farmers in the no change bracket was $72 \%$, only slightly less than the $79 \%$ of sheep and beef farmers.

Likewise, soil P fertility had no obvious effect on the farmer's likelihood of discerning the presence of a lagphase. In the Waikato, which had a lower average Olsen $\mathrm{P}$ than Taranaki and a much higher standard deviation 
in values, farmers who noted a slight initial decline were less represented than they were in Taranaki, which provided $70 \%$ of the total farmers in the survey who noted a lag-phase (Table 3 ). This may reflect the higher (and more consistent) $\mathrm{P}$ retention in Taranaki farms surveyed $(80 \%$, compared to $76 \%$ in the Waikato). Quin \& Zaman (2012) concluded that the lag-phase was most pronounced on very high $(>80 \%)$ P retention soils.

\section{Q.4 "Have you noticed any change in stock health?"}

This question was asked because of persistent anecdotal comments of improvements in stock health over the past 20 years. Over $25 \%$ said yes, and the answers suggest significant benefits are occurring on many farms (Table 4). The benefits most commonly cited included less bloat on dairy farms, and less diarrhea on sheep and beef farms. These may reflect less variability in seasonal plant nutrient content with a slow-release source of $P$.

\section{Q.5 "Are you happy with the use of RPR, and do you intend to keep using it?"}

Not surprisingly, given that all farmers interviewed were already long-term users of RPR, all expressed satisfaction, and all except one the intention to keep using it (Table 5). The only "No" was because of its perceived increasing relative cost in recent years. Many of the comments were highly positive, perhaps not a common finding in farmer surveys of any nature.

\section{Q.6 "Do you know any farmers who have stopped using RPR and why?"}

This question was asked in order to get what would possibly be more objective answers than having farmers who had stopped using it, who might feel that they were being targeted for doing this, if asked why. Surprisingly, only $14 \%$ of farmers surveyed either knew someone or had heard of some who had used RPR then stopped (Table 6). Reasons why some had stopped (as assessed by the farmer-users interviewed) included very low initial soil fertility and subsequent lack of response to RPR, reduction in the original cost advantage of RPR compared to SSP, and stopping all fertiliser application due to drought.

\section{Q.7 "What advice would you give to a farmer interested in switching to RPR"}

This question had the same basic motivation as Question 5. It needs to be kept in mind that the farmers in this survey who made the decision to use RPR all did so in a period when the efficacy of RPR in general, the extent of the lag-phase, and the relative performance of different RPRs were the subject of intense debate in the farming press. By far the most common response to this question was "Just give it a go!" (61\%) or "Give it time" $(20 \%)$ or words to that effect. Most added a supportive comment to their answer.

\section{General discussion and conclusions}

The results of this survey have indicated that RPRbased fertiliser is being continuously and successfully used on pasture across a typical New Zealand range of locations, soil types, soil factors and climates. The study confirms the results of extensive trial work conducted, especially since 1980 , showing very similar levels of production to soluble $\mathrm{P}$ from the third year of use, and supports indications of a smaller lag-phase under real-life grazing situations, rather than in mown plot conditions (Quin \& Zaman 2012).

In situations where research has indicated that a few percent lower production can be expected, at least for a few years, the farmer has the options to either simply accept this, or to use a suitable product or blend containing RPR and soluble P, either initially or longterm. The latter strategy is likely to be more important on soils with very high P retention.

There was no evidence from this survey of any differences in the performance of different RPRs used by the farmers questioned. Most expressed faith in their supplier to do the right thing, and were not necessarily aware of which country or deposit their RPR was being sourced from. This suggests that the traditional factors used to assess RPRs, viz citric acid solubility of the product as sold (Brown \& McGovern 1991) is still valid, but declining farmer knowledge of the source of the RPRs on the market suggests that the definition should be strengthened by the addition of a maximum crystal a-axis dimension of 9.340 Á (Van Kauwenbergh 1998).

The proven significantly lower losses of $\mathrm{P}$ in surface run-off with RPR compared to soluble $\mathrm{P}$ (Hart et al. 2004; McDowall \& Catto 2005; Gillingham \& Gray 2007) suggests that farmers in P-sensitive catchments should be being given far more detailed and proactive advice regarding how to use RPR in their fertiliser strategy. This advice needs to incorporate means of overcoming the risk of wind-drift on spreading fine RPR, and the resulting risk of direct entry into waterways.

\section{Recommendations for RPR use}

The results of this survey have enabled the re-evaluation of RPR field research reported by Quin \& Zaman (2012) to be further refined, resulting in the following updated recommendations for the use of RPR in New Zealand pastoral agriculture at the range of soil P levels commonly found:

1. RPR has been shown in several studies to result in lower P run-off losses from farms than when soluble $\mathrm{P}$ is used. This fact needs to be taken into 
consideration by farmers, fertiliser companies and policy makers charged with reducing eutrophication of waterways.

2. As demonstrated in earlier work, RPR is not suited for use in conditions combining high $\mathrm{pH}$ (6.3 and above) with low rainfall $(<800 \mathrm{~mm})$ without irrigation.

3. Otherwise, on all but high $(>80 \%)$ P retention soils, RPR maintains pasture production at similar levels to soluble $\mathrm{P}$ at least from the third year of use. The difference in production during the 2-year lag phase ranges from $0-5 \%$.

4. Subject to 2 above, there is no measurable lagphase at all in sites in the lower North Island and on the West Coast of the South Island.

5. On high $P$ retention soils, there are indications (not statistically significant) that the RPR lagphase is longer, with possible $3-4 \%$ lower production for up to 5 years, and a possible smaller deficit longer term.

6. There is anecdotal evidence that the lag-phase on peat soils is considerably longer than the low $\mathrm{P}$ retention would suggest. This is likely to be due to the inhibitory effect on RPR dissolution of the slowly dissolving reserves of the heavy applications of lime typically made to these soils during development. It is recommended that a blend of low-gypsum soluble P and RPR be used long term.

7. The previous maximum $\mathrm{pH}$ for RPR use of 6.0 is too conservative under higher rainfall $(1200 \mathrm{~mm}$ or above) or irrigation; the real limit, based on farmer survey data, is likely to be 6.3 .

8. More specifically, the following conclusions can be made in relation to the six regional/ rainfall/ soil P retention groupings used by Quin \& Zaman (2012):

- Group a: Northland (equates to Region 1 in Table 1).. After a 2-year lag phase averaging $5 \%$ lower production $(\mathrm{P}<0.05)$, RPR equals the performance of soluble $\mathrm{P}$.

- Group b: High to very high P retention soils of the central North Island and Taranaki (equates to Regions 2 and 3 in Table 1). Unless initial soil Olsen P levels are very high, there is a minimum 2-year lag-phase in which there is $4-5 \%$ lower production $(\mathrm{P}<0.05 \%)$ with RPR. There are indications that a slowly declining deficit may continue for several more years.

- Group c: Southern North Island, lower pH (equates to Regions 4 and 5 in Table 1). No lag phase was observed. In the third year of use, there were indications that RPR was superior to soluble $\mathrm{P}$.
- Group d: Irrigated Canterbury and low P retention soils in Southland (equates to Regions 6 and 7 in Table 1). There is a minimum 2-year lag phase in which pasture production is $5 \%$ lower $(\mathrm{P}<0.05)$ with RPR. This turns into a non-significant surplus from year 4 onwards.

- Group e: West Coast South Island (equates to Region 8 in Table 1). No lag phase has been observed, although the relative lack of early responsiveness to $\mathrm{P}$ in the trials may have influenced this. In year 5, RPR was significantly $(\mathrm{P}<0.05)$ superior.

- Group f: Southland medium-high P retention (no examples in Table 1). The lag-phase with RPR appears to be 3 years, although the difference between soluble P and RPR was significant $(\mathrm{P}<0.05)$ in years 1 and 3 only. RPR was equivalent to soluble $\mathrm{P}$ in year 4 onwards.

9. The results of the farmer survey indicate that the extent of the lag-phase is considerably less under grazing than under the mown-plot conditions of the National Series of trials. This possibility is supported by the results of the small number of soluble P vs RPR trials conducted under grazing.

10. Farmers who wish to use RPR but are concerned about the possibility of experiencing a lag-phase, particularly one of $3 \%$ production or more and lasting more than 2 years, such as those with very highly $\mathrm{P}$ retentive soils (group b), or very low soil P levels, have the option of using blends of RPR with soluble P (preferably forms other than SSP, such as DAP or TSP, as the high gypsum content of SSP can slow the dissolution of RPR in co-granulated products). The soluble P source should provide $25-30 \%$ of the total P. Granulated phosphoric or mixed phosphoric/sulphuric PAPRs are also suitable.

11. Consideration must be given to avoiding the risk of direct entry of dry RPR particles into waterways during spreading, due to its fine particle distribution. This risk can be avoided by dampening the product with $4-6 \%$ moisture, granulating, or applying the entire product (including any additives) as a high-solids fluid. Combination of these alternatives with variablerate application should be considered. The much higher bulk density of RPR compared to most soluble $\mathrm{P}$ fertilisers greatly reduces the movement of RPR particles in surface water-movement, and the particles themselves are much less soluble in water.

12. Products should only be described as RPR, and used as such by farmers, if (i) the citric solubility of the 75-1000 micron fraction in the product 
as sold exceeds $30 \%$ of the total P content, (ii) the product contains no more $3 \%$ by weight coarser than $1 \mathrm{~mm}$, (iii) the minimum total $\mathrm{P}$ (before blending with other nutrients) is $11.5 \%$ $\mathrm{P}$, and (iv) the a-axis crystal dimension of the RPR does not exceed $9.340 \AA$. Current products known to meet these criteria, and available from time to time in New Zealand, include those from Sechura (Peru), Kosseir (Egypt), Gafsa (Tunisia) and its continuation into Algeria, and selected lower manganese content Vietnamese RPRs. New Zealand's Chatham Rise phosphorite, and possibly that from Namibia, would also meet these criteria if suitably beneficiated.

\section{ACKNOWLEDGEMENTS}

The authors are grateful to Ballance Agri-Nutrients Ltd for their support of the survey and for granting access to clients, to the many staff of Ballance/Altum who assisted in the survey, and to the 54 farmers who generously gave of their time and experience to answer the questions.

\section{REFERENCES}

Brown, M.W.; McGovern, C.G 1991. Chemical and physical analysis of phosphate rocks. MAF Technology, Ruakura Agricultural Centre, Nov. 1991: 18pp.

Gillingham, A.G.; Gray, M.H. 2007. Measurement of phosphorus losses in runoff from grazed catchments receiving contrasting phosphorus fertiliser types. Report prepared for Summit-Quinphos June 2007. AgResearch 2007, 23pp.

Hart, M.R.; Quin, B.F.; Nguyen, M.L. 2004. Phosphorus runoff from agricultural land and direct fertilizer effects: a review. Journal of Environmental Quality 33: 1954-1972.

Ledgard, S.F.; Thorrold, B.S.; Sinclair, A.G.; Rajan, S.S.S.; Edmeades, D.C. 1992. Summary of eleven long-term trials with 'Longlife' phosphatic fetiliser. Proceedings of the New Zealand Grassland Association 54: 35-40.
Mackay, A.D. 1990. Comparison of phosphate fertilisers in a grazed hill country pasture. Proceedings of the New Zealand Grassland Association 51: 97-100.

Mackay, A.D.; Wewala, G.S. 1990. Evaluation of partially acidulated phosphate fertilizers and reactive phosphate rock for hill pastures. Fertilizer Research 21: 149-156.

McBride, S.D. 1992. Agronomic performance of RPR fertiliser in a grazed pasture. Proceedings of the New Zealand Grassland Association 54: 41-44.

McDowell, W.; Catto, W. 2005. Alternative fertilisers and management to decrease incidental phosphorus loss. Environmental Chemistry Letters 2: 169-174.

Quin, B.; Zaman, M. 2012. RPR Revisited (1): Research, recommendations, promotion and use in New Zealand. Proceedings of the New Zealand Grassland Association 74: 255-268.

Rajan, S.S.S.; Marwaha, B.C. 1993. Use of partially acidulated phosphate rocks as phosphate fertilizers. Fertilizer Research 35: 47-59.

Saggar,S.; Hedley, M.J.; White, R.E.; Perrott, K.W.; Gregg, P.E.H.; Cornforth, I.S.; Sinclair, A.G. 1999. Development and evaluation of an improved soil test for phosphorus, 3: field comparison of Alsen, Colwell and Resin soil P tests for New Zealand pasture soils. Nutrient Cycling in Agroecosystems 55: 35-50.

Thomson, N.; Roberts, A.H. 1995. Phosphate fertiliser - farmlet study. Research Newsletter. Taranaki Agricultural Research Station, Normanby, Taranaki, Newsletter May 1995, 3pp.

Van Kauwenbergh, S. J. 1998. Chemical and mineralogic evaluation of a phosphate rock from Egypt (Kosseir deposit) for direct application, as imported into New Zealand by Summit-Quinphos (NZ) Ltd. Report Prepared by the International Fertilizer Development Centre, Muscle Shoals, Alabama, USA, June 1998. 
